EGU21-11903

https://doi.org/10.5194/egusphere-egu21-11903

EGU General Assembly 2021

(C) Author(s) 2021. This work is distributed under

the Creative Commons Attribution 4.0 License.

\title{
Sources of water-soluble Brown Carbon at a South-Eastern European Site
}

Charalampia Baliaka ${ }^{1,2}$, Christos Kaltsonoudis ${ }^{1}$, Kalliopi Florou ${ }^{1}$, Spiro Jorga ${ }^{3}$, Christina Vasilakopoulou, ${ }^{1,2}$, John Kodros ${ }^{1}$, Andreas Aktypis ${ }^{1,2}$, Angeliki Matrali ${ }^{1,2}$, Despina Paraskevopoulou ${ }^{1,4}$, Mauro Masiol ${ }^{1,5}$, Spyros Pandis ${ }^{1,2,3}$, and Athanasios Nenes ${ }^{1,6}$ ${ }^{1}$ Institute of Chemical Engineering Sciences, (FORTH/ICE-HT), 26504 Patras, Greece

${ }^{2}$ Department of Chemical Engineering, University of Patras, 26504 Patras, Greece

${ }^{3}$ Department of Chemical Engineering, Carnegie Mellon University, Pittsburgh, PA 15213, USA

${ }^{4}$ Institute for Environmental Research and Sustainable Development, National Observatory of Athens, Palaia Penteli, 15236 Athens, Greece

${ }^{5}$ Dipartimento di Scienze Ambientali, Informatica e Statistica, Università Ca' Foscari Venezia, IT-30172 Mestre-Venezia, Italy ${ }^{6}$ Laboratory of Atmospheric Processes and their Impacts, School of Architecture, Civil and Environmental Engineering, École Polytechnique Fédérale de Lausanne, 1015 Lausanne, Switzerland

Atmospheric brown carbon $(\mathrm{BrC})$ is a highly uncertain, but potentially important contributor to light absorption in the atmosphere. Laboratory and field studies have shown that $\mathrm{BrC}$ can be produced from multiple sources, including primary emissions from fossil fuel combustion and biomass burning (BB), as well as secondary formation through a number of reaction pathways. It is currently thought that the dominant source of atmospheric $\mathrm{BrC}$ is primary emissions from $\mathrm{BB}$, but relatively few studies demonstrate this in environments with complex source profiles.

A field campaign was conducted during a month-long wintertime period in 2020 on the campus of the University of Peloponnese in the southwest of Patras, Greece which represents an urban site. During this time, ambient filter samples (a total of 35 filters) were collected from which the watersoluble $\mathrm{BrC}$ was determined using a semi-automated system similar to Hecobian et al. (2010), where absorption was measured over a $1 \mathrm{~m}$ path length. To measure the BrC, a UV-Vis Spectrophotometer was coupled to a Liquid Waveguide Capillary Cell and the light absorption intensity was recorded at 365 and $700 \mathrm{~nm}$. The latter was used as a reference wavelength. We found that the average $\mathrm{BrC}$ absorption in Patras at a wavelength of $365 \mathrm{~nm}$ was $8.5 \pm 3.9 \mathrm{Mm}^{-1}$ suggesting that there was significant $\mathrm{BrC}$ in the organic aerosol during this period. Attribution of sources of BrC was done using simultaneous chemical composition data observations (primarily organic carbon, black carbon, and nitrate) combined with Positive Matrix Factorization analysis. This analysis showed that in addition to the important role of biomass burning (a contribution of about 20\%) and other combustion emissions (also close to 20\%), oxidized organic aerosol (approximately $40 \%$ ) is also a significant contributor to $\mathrm{BrC}$ in the study area.

\section{Reference}


Hecobian, A., Zhang, X., Zheng, M., Frank, N., Edgerton, E.S., Weber, R.J., 2010. Water-soluble organic aerosol material and the light-absorption characteristics of aqueous extracts measured over the Southeastern United States. Atmos. Chem. Phys. 10, 5965-5977. https://doi.org/10.5194/acp-10-5965-2010 